\title{
Choledochoduodenal fistula after biliary placement of a self-expanding metallic stent for palliation of pancreatic cancer
}

A 56-year-old man with pancreatic cancer underwent palliative placement of a biliary self-expanding metallic stent (SEMS) for obstructive jaundice after chemoradiation (nine cycles over 5 months). He presented with melena but denied abdominal pain, nausea/vomiting, or hematemesis. Hemoglobin concentration was $6.5 \mathrm{~g} / \mathrm{dL}$ and serum bilirubin $1.0 \mathrm{mg} / \mathrm{dL}$ (normal: $13.8-17.2 \mathrm{~g} / \mathrm{dL}$ and $<1.9 \mathrm{mg} / \mathrm{dL}$, respectively). Abdominal CT with intravenous contrast showed pneumobilia and mucosal hyperenhancement in the gastroduodenal area. After blood transfusion, an upper endoscopy was performed which showed that the duodenal bulb was extrinsically compressed and eroding medially through the duodenal wall with the covered biliary SEMS ( $\bullet$ Fig. 1 ) surrounded by a large circumferential ulcer

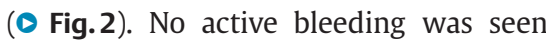
and no therapeutic intervention was performed. The patient continued to have melenic stools. Subsequent colonoscopy was unremarkable. Mesenteric angiography was performed in attempt to prophylactically embolize the gastroduodenal artery, but was technically unsuccessful because of a narrowed gastroduodenal artery which was not actively bleeding. The patient died from exsanguination later that day.

Choledochoduodenal fistula (CDF) is a rare complication of SEMS caused by tumor invasion, stent migration [1], or chemoradiation, with a $3 \%-5 \%$ incidence of spontaneous biliary-enteric fistula [2]. CDF associated with SEMS induced by chemoradiation has not been previously reported. In our patient, thinning of the

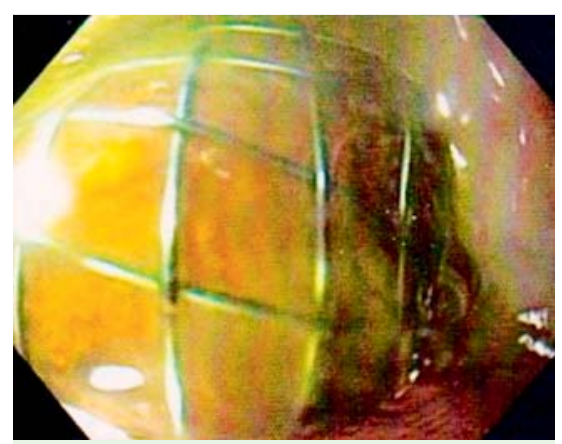

Fig. 1 Biliary stent in a 56-year-old man with pancreatic cancer, placed to treat obstructive jaundice following chemoradiation.

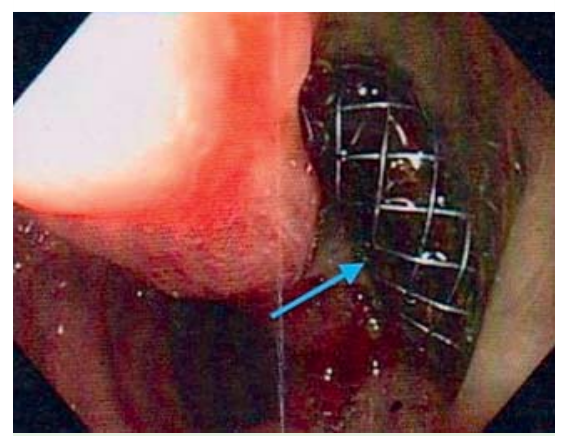

Fig. 2 Duodenal ulceration around the stent.

posteromedial duodenal wall secondary to chemoradiation and tumor burden was considered to be responsible for spontaneous CDF as a delayed complication of stent placement.

Endoscopy_UCTN_Code_CPL_1AK_2AI

Competing interests: None
D. Chaudhari ${ }^{1}$, A. Saleem ${ }^{2}$, R. Murthy ${ }^{2}$, T. Baron ${ }^{3}$, M. Young 2

${ }^{1}$ Department of Internal Medicine, East Tennessee State University, Johnson City, Tennessee, USA

${ }^{2}$ Department of Gastroenterology, East Tennessee State University, Johnson City, Tennessee, USA

${ }^{3}$ Department of Gastroenterology, Mayo Clinic, Rochester, Minnesota, USA

\section{References}

1 Saranga B, Rao P, Ghosh K. latrogenic duodenal perforations caused by endoscopic biliary stenting and stent migration: an update. Endoscopy 2006; 38: 1271-1274

2 Lee TH, Park SH, Kim SP et al. Spontaneous choledochoduodenal fistula after metallic biliary stent placement in a patient with ampulla of vater carcinoma. Gut Liver 2009; 3: $360-363$

Bibliography

Dol http://dx.doi.org/

10.1055/s-0032-1326266

Endoscopy 2013; 45: E77

(c) Georg Thieme Verlag KG

Stuttgart · New York

ISSN 0013-726X

Corresponding author

\section{Chaudhari, MD}

Department of Internal Medicine

East Tennessee State University

1008 Quality Circle, Apt \#79

Johnson City

TN 37615

USA

Fax: +1-423-7419292

Chaudharidhara@yahoo.com 